\title{
The Course of Leprosy in an immigrant population in the Netherlands
}

\author{
D. L. LEIKER \\ Dermatologist, Royal Tropical Institute, Amsterdam, Netherlands
}

\section{INTRODUCTION}

Shortly before Indonesia became independent, those Ambonese who were in the DutchIndonesian Army or who for other reasons feared repercussions, were offered facilities to move, together with their families, to the Netherlands.

Because of shortage of houses in post-war Netherlands, and because it was generally believed that the sojourn in Holland would not be of long duration, a number of camps were allocated to the immigrants. Most Ambonese preferred the camps to houses outside, in order to preserve their culture and pattern of life, rather than face the risk of becoming absorbed by the foreign community.

After a number of years it became clear that return to Indonesia had to be postponed. Many men had found work outside the camps, some families had moved to houses outside, but the great majority continued to live in the camps.

After 1958, however, the authorities actively suggested and facilitated the transfer to private houses. Many people responded, but others refused the transfer for fear of losing their identity and especially for fear that their children would lose the desire to return to the home land. After 1960, however, the number that left the camps markedly increased and at present only some rather small camps remain.

On arrival a large proportion of the immigrants were young people, unmarried or with a family of only one or a few small children. Many of the former married soon. The birth rate in these families was high. The death rate in children was low. Between 1951 and 1958 the population increased from about 13,000 to about 18,000. Camps and houses became heavily populated, if not crowded, with young children.
THE COURSE OF LEPROSY

At present a total of 37 Ambonese leprosy patients are registered, a prevalence of about 2 per 1,000. In only 10 patients, however, the symptoms of the disease were already present on arrival, a prevalence of only 0.8 per 1,000 . In the first 5 years after arrival 23 new patients appeared. In the second 5 years period only 4 more new patients were found. In the last 5 years no more new patients were found. It appears that the incidence of the disease increased markedly soon after arrival, but that thereafter a rapid decrease occurred. At present the disease is rapidly disappearing completely in the Ambonese.

\section{CHANCE OF INFECTION}

Of the 37 patients, 9 are lepromatous, 15 are intermediate and 13 are tuberculoid. Of the patients with an intermediate form of leprosy, several were temporarily bacteriologically positive in routine examinations. The number of open patients seems to be high enough for at least some spread of the disease in the community.

Some patients were temporarily hospitalised in general hospitals or in a small leprosy sanatorium. They lived, however, for considerable periods in the camps while they were still positive. Several others were never hospitalised.

The average number of house contacts was high. House contact was not limited to the family proper but included many members of the extended family.

\$. Medical Adviser on Leprosy of the Gastmann Wichers Foundation at Rotterdam and of the Dermatological Department of the Universities at Amsterdam and Utrecht. 
The average age of contacts was low. In a survey in one of the camps it was found that $20 \%$ of the inhabitants were children below the age of 5 and $40 \%$ were between 5 and 15 years old. The houses frequently were rather overcrowded.

It seems that the conditions for spreading of the disease were very favourable.

\section{COURSE OF LEPROSY IN INUO-EUROPEAN}

\section{IMMIGRANTS}

The course of leprosy in part European immigrants corresponds with the findings in the Ambonese. Of 245 patients registered since 1946, 184 already had signs of the disease before arrival. In the 61 other patients the first signs were noticed in 49 patients in the first 5 years after arrival and in only 12 patients in the second 5 years after arrival (Table 1 ).
Ambonese. In this close community it is difficult to conceal the signs of the disease for a long time. More advanced patients would be noticed and become known to the local physicians, who often are Ambonese themselves. Co-operation between camp physicians and the treatment centre at Rotterdam has always been excellent. The great majority of patients were registered and treated in this Centre and practically all patients treated elsewhere are known.

The families of all known patients have been examined annually. Very few new patients have been found in these families. In 1960 an intensive survey in one of the camps was carried out. In 832 people no new patients were found. It is believed that practically all leprosy patients in the Ambonese are known.

In Indonesia risk of infection existed not only within the group but also outside, by contact

TABLE 1

Relationship between onset of disease and time of arrival in the Netherlands

\begin{tabular}{|c|c|c|c|c|c|c|c|c|c|c|c|}
\hline \multirow[b]{2}{*}{ No. of years : } & \multicolumn{6}{|c|}{ Onset before arrival } & \multicolumn{5}{|c|}{ Onset after arrival } \\
\hline & $10+$ & $8-9$ & $6-7$ & $4-5$ & $2-3$ & ()- 1 & $1-2$ & $3-4$ & $5-6$ & $7-8$ & $9-10$ \\
\hline Ambonese & 0 & 1 & 1 & 0 & 1 & 7 & 9 & 14 & 3 & 0 & $1 *$ \\
\hline Indo-Europeans & 53 & 11 & 15 & 17 & 40 & 48 & 32 & 17 & 6 & 4 & 2 \\
\hline Total & 53 & 12 & 16 & 17 & 41 & 55 & 41 & 31 & 9 & 4 & 3 \\
\hline
\end{tabular}

* In this patient some evidence of an earlier initial lesion was found.

\section{DISCUSSION}

The question may be asked if the figures truly represent the course of the disease in the Ambonese. Because leprosy is feared, hiding of patients would be likely. In the first years after arrival some patients came forward for treatment after considerable delay. After it became more widely known, however, that compulsory segregation was not practised, effective treatment free of charge was available, that social assistance was given to patients and that they did not need to fear interference with their daily occupation, most patients came forward voluntarily and attended for treatment regularly. Defaulters were, usually without great difficulty, persuaded by the social worker to resume treatment. Leprosy is well known by the with members of other population groups. The marked increase in the incidence of leprosy in the first 5 years after arrival in the Netherlands, therefore, is somewhat unexpected. One would expect a decrease. In Indonesia leprosy patients frequently were not allowed to stay in the military camps or they left the camps on their own initiative. In the Netherlands, patients remained in the camps. It is unlikely, however, that this is the reason for the increase. Because of the long incubation period, one would expect an increase in the second 5 years period after arrival and not so soon after arrival. It is more likely that the temporary increase has to be explained by the unusual circumstances before departure. The people were concentrated in a number of camps, frequently under rather

\section{Leprosy Review}


unfavourable condition, and they were transported on ships that were very crowded. The transmission rate probably was higher than usual shortly before departure and during the voyage.

The marked decrease in the incidence of leprosy that followed the temporary increase cannot easily be explained by the factors influencing the epidemiology of leprosy that are usually mentioned, e.g., isolation, improved hygiene, etc. The climate in the Netherlands has not changed essentially since the time that leprosy was endemic. Tuberculosis cannot have been the main factor as the incidence of tuberculosis decreased in the Netherlands. The use of more and of thicker clothes may have reduced the incidence of patients infected outside the family, but does not offer an explanation for the fact that the incidence of new patients in children in families with infectious parents has been so low.

In our opinion a factor of major importance is that most patients were treated in a reasonably early stage of the disease and that they have attended regularly. Lepromatous patients may remain bacteriologically positive for many years under treatment, but the percentage of morphologically intact bacilli rapidly decreases after regular, adequate treatment. Such patients probably are much less infectious or even noninfectious under European conditions. So far only one patient with leprosy, a man who has never visited an endemic country and who had no known contact with patients in the Netherlands, has been discovered (Beek, 1961).

The immigration of numerous leprosy patients in non-endemic countries in Europe at present creates some difficulties. The experience in the Netherlands is reassuring. There is no need for restrictions, provided the medical practitioners have a working knowledge of leprosy that enables them to suspect leprosy in an early stage of the disease.

In order to render the patient less contagious in the shortest possible time, and to reduce the chance of disability, patients should be treated by experts or at least be treated under the supervision of experts. Central registration of patients is needed for following the trend of the disease. If treatment is free, some social assistance is offered and no restrictions are enforced on patients, the great majority will come forward voluntarily. Defaulters, however, should be traced and persuaded to start or to resume treatment. In our experience only exceptional patients are persistently non-co-operative. Such patients doubtless are a danger, although under European conditions they are not a great danger.

Even in such cases the use of compulsion is as a rule not a remedy. Direct or indirect force results in a greater number of patients that report only in a more advanced stage of the disease or abscond from treatment.

The findings also are encouraging for mass treatment campaigns in endemic countries. Such campaigns, however, become really effective only if serious attempts are made to get the great majority of patients on treatment in an early stage and regularly and if the treatment is adequate.

SUMMARY

The incidence of leprosy decreased rapidly in Ambonese and Indo-European immigrants already in the second 5 years after arrival in the Netherlands, despite conditions that seemed favourable for spreading of the disease. The main reason for decline of leprosy is the regular treatment of patients which rendered patients less or non-infectious even while they were still bacteriologically positive.

Early and regular attendance should be encouraged by offering patients facilities. Restrictions forced on patients result in nonco-operation and have an adverse effect.

\section{REFERENCES.}

BEEK, C. H. Een autochtoon geval van lepra in Nederland. Ned. Tijdschrift voor Geneeskunde, 105, $1961,2,214$.

LEIKER, D. L. Leprosy in the Netherlands. Lep. Rev,. $31,4,290,1960$. 